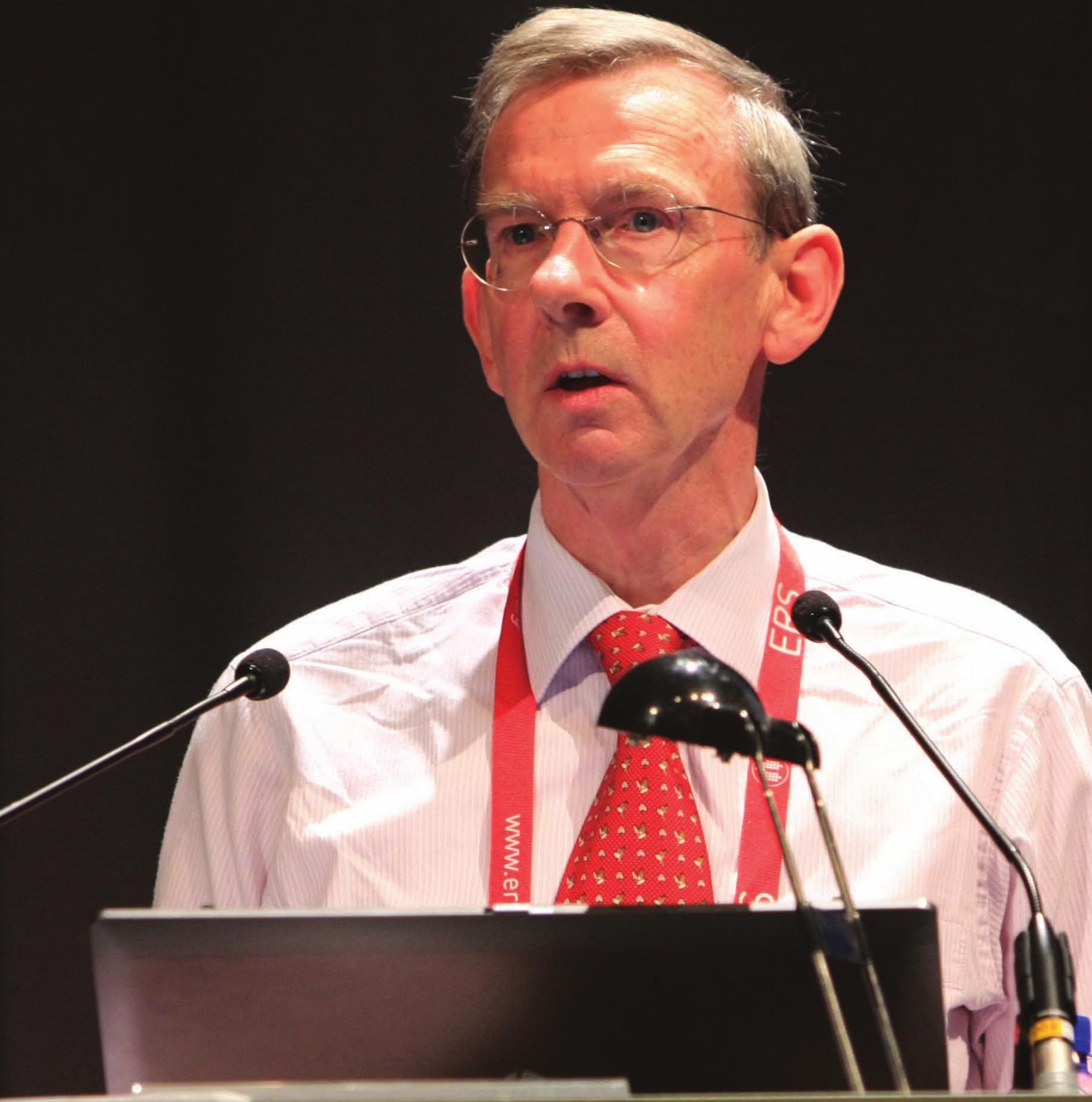

\title{
EUROPEAN RESPIRATORY SOCIETY
}

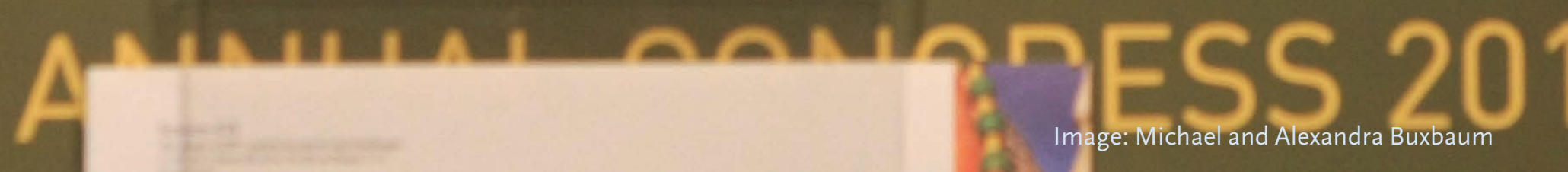




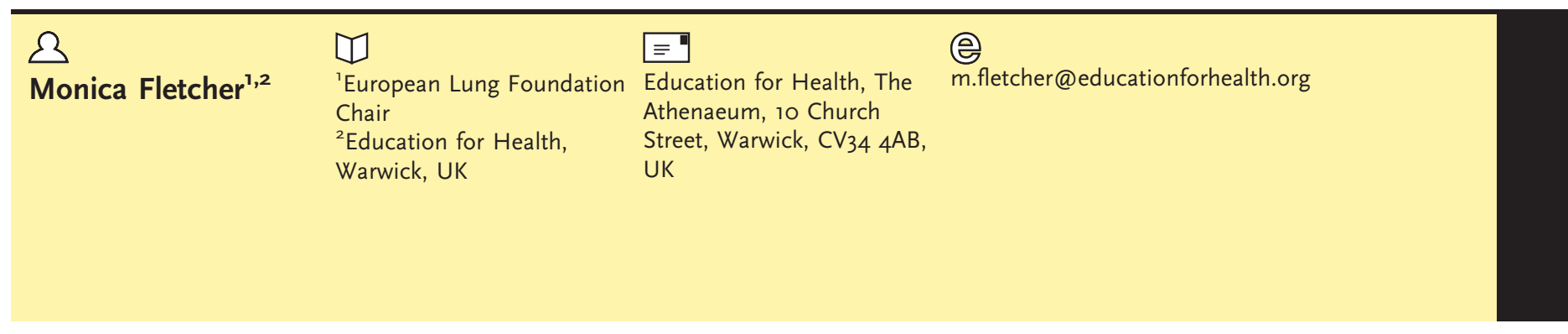

\section{Public and patient involvement in action at the ERS Annual Congress 2013}

This Editorial follows on from my contribution in the last edition of Breathe, which discussed the current status of patient and public involvement (PPI) in healthcare in Europe [1], by giving examples of how the European Lung Foundation (ELF) is making sure PPI is a key part of the biggest annual respiratory congress in the world.

\section{The patient voice in symposia}

We were delighted this year to have a range of patients speaking in symposia as part of the main scientific programme for the first time. The patients spoke on a range of issues including: their personal experience of living with cystic fibrosis and the optimal time for lung transplantation, the importance of telemedicine for all patients to reduce time spent in clinic and hospital and the impact of a diagnosis of idiopathic pulmonary fibrosis (IPF). These personal testimonies worked well in all sessions, and were carefully and sensitively woven into the main symposia by the session chairs. All of the patients who took part had a really positive experience and all encouraged some interesting questions and discussion with the audience. ELF will work with the programme committee for the 2014 Congress to facilitate more of these opportunities.

\section{Educating about patient involvement}

As part of the 2013 Congress programme, ELF put together a symposium entitled "Effective engagement of patients and the public in science, healthcare and the media". The aim was to inform scientists and healthcare professionals about the advantages that can be obtained from patient involvement using real-life examples from clinical trials, guideline development and media.

The session was opened by an overview of the landscape of patient involvement in healthcare across Europe, drawing on the results from a respiratory patient organisation survey that ELF conducted earlier in the year (available online [2]). The data illustrate the great number of patient organisations that are working across Europe to improve lung health, and their motivation to expand their activities from support and information to developing clinical guidelines and setting the research agenda. Data were also presented on how ELF is supporting patient advocates through the European Patient Ambassador Programme (www.EPAPonline.eu).

The second presentation of the session was given by Lina Buzermaniene, parent of a child with asthma and a member of the European Federation of Asthma and Airways Diseases Patients Association (EFA). Lina
Statement of Interest None declared. 
talked about the emerging roles for patients in clinical trials. Using the U-BIOPRED (www. UBIOPRED.eu) study as an example, she highlighted the pragmatic value of patient partners in research projects and their ability to enhance recruitment, compliance, research transparency and dissemination.

One of the most thought-provoking talks in the session was from Antoine Boivin from the Guideline International Network (G-I-N), who brought patient input alive by describing his work on the first patient-involvement randomised controlled trial [3]. He clearly demonstrated the benefits that patient involvement can bring, but warned of the difficulties of measuring impact and trying to meet research gold standards to gain acceptance from members of the healthcare community who are cynical about patient involvement. To overcome this, he proposed that more systematic multi-way communication is needed between patients and healthcare professionals.

The session line-up was expertly concluded by Viviane Parry, a UK-based journalist with years of experience in healthcare reporting. She explained the role of the patient in ensuring science reporting in the media is fair and balanced. She shared the "tricks of the trade", such as selling research stories with real-life patient stories to raise media interest.

The slides for all the talks from this insightful session are available free to access on the European Respiratory Society's (ERS's) e-learning resources website [4].

\section{Patient involvement in action}

One of the most impactful and inspiring aspects of the congress in Barcelona was seeing some true patient involvement in action.

One such session was a preparatory meeting concerning the potential revision of ERS/American Thoracic Society guidelines for the diagnosis and management of IPF. ELF had been approached about this revision, which specifically wanted to look at the patient experience. Therefore, a meeting was convened during the congress with the leads of the Task Force group working on the guidelines and patient organisation representatives - on this occasion members of the Irish Lung Fibrosis Association (ILFA). In preparation for the meeting, ILFA had held focus group discussions with carers and patients with IPF. From this, ILFA compiled a report incorporating patient concerns and hopes for the future, which was shared with ELF and the IPF experts prior to the meeting. The meeting was well attended, with six of the world's leading IPF experts present along with five patients and carers.

There was an constructive discussion about what patients want and expect from doctors, the importance of early referral for assessment for transplantation, medication, the need for discussions with patients about surgical biopsies, future planning and palliative care, and the importance of communication and empathy. The meeting was a great success and the patients who attended left feeling pleased to have been able to contribute in such a unique way.

So what happens next? ELF will continue to work with ILFA and will also invite other European IPF patient organisations to participate in the process. These organisations will be asked to establish common themes and concerns among IPF patients and carers. Commentating on how she felt about the experience, Nicola Cassidy, on behalf of ILFA, stated: "I feel genuinely optimistic that this is a worthwhile and positive venture."

\section{The future of patient involvement in the ERS}

The ERS is currently in a process of strategic review - preparing the society for an exciting and growing future at the heart of respiratory health in Europe and across the world. As part of that process, a review of the role of ELF and how it sits in the society is also taking place. A clear message that has come from the ERS regarding this strategy is that ELF should be focused on patients. It should be the vehicle through which patients can be involved at all levels of the society and really share in the advances in healthcare that are being pushed forward. One major change that has been proposed is that the person who replaces me as Chair of the ELF may be a patient or patient representative. This is a great advancement and would truly place patients at the centre of healthcare research and decision-making.

We held a strategic session at the Congress with all 20 patient organisations that joined us in the World Village, as well as 
members of the ERS leadership, to discuss what they view as their hopes and goals for the future. There is so much synergy and shared vision for the future of lung health in Europe and across the world (a copy of the report of the meeting is available online [5]). I very much look forward to working with our patient organisation committee and the ERS in this coming year to bring many more of these dreams to fruition. I am optimistic that patients' voice will grow to be more and more influential in the society. I am proud to say the ERS is really leading the way in PPI and I hope you are too.

If you want to get involved please contact us through our website, www.europeanlung.org.

\section{References}

1. Fletcher M. Are patients shaping healthcare across Europe? Breathe 2013; 10: 333-334.

2. European Lung Foundation. Results of our 2013 patient organisation survey. www.europeanlung.org/en/newsand-events/news/results-of-our-2013-patient-organisationsurvey Date last accessed: October 162013.

3. Boivin A. Patient and Public Involvement in Healthcare Improvement. Ph.D thesis, Radboud Universiteit Nijmegen, Netherlands, 2012. Available at http://repository.ubn.ru.nl/bitstream/2066/95112/1/ 95112.pdf Date last accessed: October 162013.
4. European Lung Foundation, European Respiratory Society. Effective engagement of patients and the public in science, healthcare and the media. www.erseducation.org/events/annual-congress. aspx?idParent $=125379$ Date last accessed: October 16 2013.

5. European Lung Foundation, European Respiratory Society. Report on the ELF Strategic Session. www. europeanlung.org/en/assets/files/en/publications/elf_ strategic_session_report.pdf Date last accessed: October 312013. 